\title{
Efficacy of infliximab in refractory Behçet's disease-associated and idiopathic posterior segment uveitis: a prospective, follow-up study of 50 patients
}

\author{
This article was published in the following Dove Press journal: \\ Biologics:Targets and Therapy \\ 28 December 2011 \\ Number of times this article has been viewed
}

\section{Fabrizio Cantini' \\ Laura Niccoli' \\ Carlotta Nannini' \\ Olga Kaloudi' \\ Emanuele Cassarà' \\ Massimo Susini ${ }^{2}$ \\ Ivo Lenzetti}

'Second Division of Internal Medicine, Rheumatology Unit, ${ }^{2}$ Division of Ophthalmology, Prato Hospital, Prato, Italy
Correspondence: Fabrizio Cantini Rheumatology Division, Ospedale Misericordia e Dolce, Prato, Piazza Ospedale, I - 59100 - Prato, Italy Tel +390574434572

Fax +39057443442 I

Email fbrzcantini@gmail.com
Purpose: To evaluate the long-term efficacy of infliximab in patients with refractory Behçet's disease (BD)-associated and idiopathic posterior uveitis (PU).

Methods: Single center, prospective, 6-year duration, follow-up study on 50 consecutive patients (20 [40\%] males and 30 [60\%] females with a mean age of $37.5 \pm 12.3$ years) with refractory BD-associated PU (36 patients) and idiopathic PU (14 patients) who had failed at least one immunosuppressive drug. At baseline, patients received prednisone $1 \mathrm{mg} / \mathrm{kg} /$ day with rapid tapering and infliximab infusions $(5 \mathrm{mg} / \mathrm{kg}$ ) at weeks $0,2,6$, and every 8 weeks thereafter. Nonresponders after the third infusion withdrew from the study. Primary outcome measures were visual acuity (VA) value improvement compared to baseline. Secondary outcome measures were proportion of patients with VA improvement from baseline; proportion of patients achieving disease remission; number of PU flare-ups; and incidence of adverse events.

Results: At the final follow-up, mean right and left eye VA respectively increased from $0.57 \pm 0.31$ at baseline to $0.68 \pm 0.33(P=0.048)$ and from $0.67 \pm 0.28$ to $0.76 \pm 0.27$ $(P=0.047)$. None of the patients had VA worsening and new onset ocular complications. A complete response of $\mathrm{PU}$ was recorded in 34/50 (68\%) patients and partial response in 11/50 $(22 \%)$. Five patients were nonresponders and withdrew from the study after the third infusion. A significant reduction of ocular attacks and of the proportion of patients with cystoid macular edema was observed. No differences in infliximab efficacy was recorded between patients with BD-associated and idiopathic PU. No serious adverse events occurred. The mean follow-up duration was 36.8 months.

Conclusion: Long-term infliximab therapy was equally effective and safe with a significant VA gain in refractory BD-associated and idiopathic PU.

Keywords: Behçet's disease, idiopathic posterior uveitis, infliximab, posterior uveitis, visual acuity

\section{Introduction}

Noninfectious posterior uveitis (PU) are immune-related, sight-threatening inflammatory conditions that account for $22 \%$ to $38 \%$ of all cases of uveitis seen in tertiary care centers. ${ }^{1-4}$

According to the Standardization of Uveitis Nomenclature (SUN) working group classification, the inflammatory process of PU may involve the choroid and the retina causing variable clinical patterns such as focal, multifocal, diffuse choroiditis, chorioretinitis, retinochoroiditis, retinitis, or neuroretinitis. ${ }^{5}$ As reported in a recent systematic review 
of the literature, ${ }^{6}$ PU are mainly caused by Behçet's disease (BD), serpiginous choroiditis and sarcoidosis, otherwise PU remain idiopathic in around $35 \%$ of cases.

BD-associated PU and idiopathic PU, with or without associated retinal vasculitis, share a relapsing and remitting clinical course with frequent occurrence of ocular complications such as cataract, cystoid macular edema, retinal detachment, papillitis, and intraretinal/subretinal hemorrhages, with progressive worsening of visual function leading to blindness in up to $25 \%$ of patients. ${ }^{7}$ Over a 30 -year period, a trend toward improvement of prognosis has been recorded by treating the disease with high-dose corticosteroids (CS) combined with traditional immunosuppressive drugs including methotrexate, cyclosporine (CsA), azathioprine (AZA), and cyclophosphamide. ${ }^{8}$ However, PU may be particularly resistant to CS and immunosuppressants with rapid progression to vision loss in $10 \%-25 \%$ of cases. ${ }^{9,10}$

The inflammatory process of both BD-associated and idiopathic PU is sustained by a Th1-mediated response with increased secretion of proinflammatory cytokines including interleukin-1, interleukin-6, and especially tumor necrosis factor alpha (TNF $\alpha)$ that has been demonstrated to play a pivotal role in the pathogenesis of autoimmune uveitis. ${ }^{11-17}$

Following this evidence, the efficacy of anti-TNF agents including infliximab (IFX) and adalimumab in patients with refractory BD-associated or idiopathic PU has been reported in recent open, short-term studies of small clinical series. ${ }^{18}$

The long-term efficacy of anti-TNF therapy was confirmed by our group in an open-label, 24-month, prospective, follow-up study on 12 patients with BD and refractory posterior uveitis receiving IFX $5 \mathrm{mg} / \mathrm{kg}$. A complete remission after the third infusion in six patients and in nine after the fourth was recorded, with maintenance of remission in seven out of nine patients at the 24-month visit. ${ }^{19}$

The primary objective of this prospective study was to evaluate the efficacy of IFX therapy in terms of improvement in visual acuity (VA) in a cohort of consecutive patients with refractory idiopathic PU and BD-associated PU.

\section{Patients and methods \\ Setting}

The Rheumatology Unit of Prato Hospital is a secondary referral center which serves around 300,000 people living in the Prato province and the surrounding industrial areas. About $75 \%$ of patients are sent by their general practitioners, and the remaining are self-referred.

In March 2004, the Rheumatology Unit was appointed as the tertiary referral center for rare rheumatic diseases.
Patients with these conditions are self-referred or sent by other specialists from all parts of Italy.

From January 2005 to December 2010, in collaboration with the Ophthalmology Department of Prato Hospital, all consecutive new patients with refractory PU underwent the same diagnostic and therapeutic schedule and all data were recorded in an individual computed chart.

At baseline all patients underwent the following investigations: history taking, physical examination, purified protein derivative (PPD) test, laboratory tests including erythrocyte sedimentation rate (ESR), C-reactive protein (CRP), blood cell count with differential count, renal and liver function, human leukocyte antigen typing, antinuclear antibody titer, and serology for toxoplasma, human immunodeficiency virus, syphilis, lysozyme, or angiotensin-converting enzyme. Ophthalmologic evaluation consisted of a complete ocular examination including best-corrected VA (Snellen chart of 0.1-1.0), slit-lamp biomicroscopy, tonometry and ophthalmoscopy, optical coherence tomography (OCT), and fundus fluorescein angiography (FFA).

\section{Inclusion criteria}

To be enrolled, patients should have a diagnosis of idiopathic or BD-associated chronic PU, with or without retinal vasculitis, resistant to a dose of prednisone or equivalent greater than $10 \mathrm{mg} /$ day, and at least one immunosuppressive drug after at least 12 months of treatment. ${ }^{20}$

The diagnosis of BD was formulated according to the International Study Group (ISG) criteria. ${ }^{21}$ As VA loss during BD flare-ups may be reversible following treatment, ${ }^{22}$ we also included in the study patients with active PU and unilateral or bilateral loss of vision of recent onset ( $<3$ months).

\section{Exclusion criteria}

Patients with permanent blindness, with contraindications to IFX use, as recommended by by Centocor Ortho Biotech, Inc (Malvern, PA), or with a history of recent infections and malignancies were excluded from the study. Pregnancy and breastfeeding constituted additional exclusion criteria and contraception was recommended to all females of childbearing potential.

Moreover, a careful screening for tuberculosis was made by detailed medical history, chest X-rays, and PPD test. Over the last 3 years the QuantiFERON TB Gold test was also performed.

\section{Primary end-point}

The primary end-point was to assess the long-term efficacy of IFX therapy in patients with idiopathic or BD-associated 
refractory PU uveitis as expressed by VA improvement from baseline.

\section{Secondary end-points}

Secondary end-points were to investigate the efficacy of IFX to reduce disease flare-up, to assess the proportion of relapsefree subjects at the end of follow-up, and the percentage of patients achieving a complete or partial remission, and to evaluate the tolerability and safety of the treatment.

\section{Primary outcome measure}

The primary outcome measure was improvement in VA mean values at the end of follow-up compared to baseline.

\section{Secondary outcome measures}

Secondary outcome measures were a proportion of patients achieving an improvement of best-corrected right eye and left eye VA from baseline; proportion of patients achieving a complete or partial remission; timing of remission; proportion of relapse-free patients at the end of follow-up; number of ocular attacks during the treatment period; and number and severity of adverse events (AEs).

\section{Definition of response}

The response to therapy was calculated by a composite score from 0 to 7 obtained by the sum of the grade of severity of inflammatory infiltrate and retinal vasculitis as reported previously. ${ }^{19}$ The response was graded as follows:

- Complete remission: presence of less than $1+$ cellular reaction (scale $0-4$ ), and remission of vasculitis evaluated by a score (0-3) at fundus examination and FFA ( 0 = absence of vasculitis, $1=$ vasculitis of peripheral retinal vessels, 2 = posterior pole vasculitis, and 3 = vasculitis with evidence of areas of retinal necrosis). FFA examinations were scheduled at baseline, week 6 , 22 , and 54 , and yearly thereafter.

- Partial remission: improvement of at least $50 \%$ of inflammation and retinal vasculitis scores.

- Absent: absence of any improvement or less than $50 \%$ of uveitis scores.

\section{Treatment regimen}

At baseline, all patients suspended the current immunosuppressive therapy, and received prednisone at the dose of $1 \mathrm{mg} / \mathrm{kg} /$ day. In addition, all subjects received IFX 2-hour intravenous infusions at the dose of $5 \mathrm{mg} / \mathrm{kg}$ at weeks 0 , 2,6 , and every 8 weeks thereafter. IFX-dose escalation through infusion-interval shortening to 6 weeks was allowed in nonresponder patients or in those with partial remission according to the judgment of the physician. IFX infusions were administered for the whole duration of follow-up.

During the drug infusion and for 1 hour afterwards, blood pressure, pulse, and temperature were measured every 30 minutes. Moreover, at every visit, complete blood count, liver, and kidney function tests were examined. Antinuclear antibodies (ANA) were measured at baseline and every 6 months.

In responders, the following $\mathrm{CS}$-dose tapering was scheduled: $10 \mathrm{mg} /$ day every 1 week until the dose of $20 \mathrm{mg} /$ day, then $5 \mathrm{mg} /$ day/week until a maintenance dose of $10 \mathrm{mg} /$ day is achieved. This dose was continued for at least 2 weeks before attempting to further reduce the dose of $5 \mathrm{mg} /$ week until withdrawal. In case of relapse, prednisone was increased by $20 \mathrm{mg}$ /day. Other immunosuppressant agents and concomitant local CS injections were not allowed.

Patients failing to achieve at least a partial remission after the third infusion of IFX withdrew from the study and received prednisone $1 \mathrm{mg} / \mathrm{kg} /$ day and an immunosuppressant different from that employed before the study entry.

All patients had a complete evaluation by an ophthalmologist and a rheumatologist at baseline and over the follow-up visits that were scheduled 2 weeks after the third IFX infusion (week 8) and then every 4 months or before in case of relapse. The date of last visit constituted the end of follow-up.

\section{Adverse events}

At every visit, all patients were monitored for clinical and laboratory evidence of adverse events (AEs) defined as mild (transient and easily tolerated), moderate (subject discomfort with interruption of usual activities), or severe (incapacitating or life-threatening). The study was approved by the local ethical Committee and written informed consent from the patients was obtained.

Data statistical analysis was done using the SPSS statistical package (SPSS Inc, Chicago, IL). Wilcoxon's matched pairs signed rank test were used to measure the changes from baseline of ocular inflammation and ocular attacks. Chi-square test for nominal variables was used to calculate the differences between the BD-associated and idiopathic PU results. Analysis of variance (ANOVA) for repeated measures was used to measure the VA changes. $P$ values less than 0.05 were accepted as significant.

\section{Results}

Over a 6-year enrolment period, 50 patients with refractory PU (20 males [40\%] and 30 females [60\%] with a mean 
age of $37.5 \pm 12.3$ years) were included into the study. BD-associated PU was diagnosed in 36 patients (15 males [42\%] and 21 females [58\%] females with a mean age of $36.1 \pm 10.9$ years), and idiopathic PU in 14 patients (five males [36\%] and nine females [64\%] with a mean age of $40.9 \pm 15.3$ years). The demographic and clinical characteristics of the 50 patients are summarized in Table 1.

At the end of the follow up a complete response of PU was recorded in 34/50 (68\%) patients, partial response in $11 / 50(22 \%)$, and five (10\%) patients showed no improvement after the third IFX infusion and withdrew from the study as dictated by the study protocol. Of these, three had BD with bilateral PU and cystoid macular edema, and two had idiopathic PU without macular increased thickness.

As shown in Table 2, the proportions of patients with VA improvement after the third IFX infusion and at the end of the follow up were $72 \%$ (36 patients) and 82\% (41 patients), respectively. Mean right eye VA increased from $0.57 \pm 0.31$ at baseline to $0.63 \pm 0.32$ at week 8 , and $0.68 \pm 0.33(P=0.048)$ at the end of follow-up. Mean left eye VA improved from baseline value of $0.67 \pm 0.28$ to $0.74 \pm 0.26$ after the third infusion and to $0.76 \pm 0.27(P=0.047)$ at the last visit. None of the patients had worsening VA or new onset ocular complications including retinal detachments, papillitis, intra- or subretinal hemorrhage, intravitreal hemorrhage, and optic atrophy during the follow-up. A significant reduction of overall ocular attacks, proportion of patients with retinal vasculitis, and cystoid macular edema was recorded.

At the end of the follow-up, a significant improvement of VA from baseline value was observed either in BD-associated PU (right eye: $0.56 \pm 0.32$ vs $0.65 \pm 0.33, P=0.0005$; left eye: $0.68 \pm 0.27$ vs $0.76 \pm 0.27 ; P=0.0004)$ and in idiopathic PU (right eye: $0.6 \pm 0.31$ vs $0.70 \pm 0.31 ; P=0.011$; left eye: $0.65 \pm 0.30$ vs $0.75 \pm 0.29 ; P=0.016$ ). Table 3 summarizes the separated results in patients with idiopathic PU and in those with BD-associated PU. The results of efficacy of

Table I Baseline demographic and concurrent clinical manifestations in 50 patients with idiopathic and Behçet's disease-associated posterior uveitis

\begin{tabular}{|c|c|c|c|}
\hline & Overall & Idiopathic PU & BD-associated PU \\
\hline Patient number & 50 & 14 & 36 \\
\hline Male/female (no/\%) & $20(40 \%) / 30(60 \%)$ & $5(36 \%) / 9(64 \%)$ & I5 (42\%)/2I (58\%) \\
\hline Age at first visit (years/mean $\pm S D$ ) & $37.5 \pm 12.3$ & $40.9 \pm 15.3$ & $36.1 \pm 10.9$ \\
\hline Disease duration (months/mean $\pm \mathrm{SD}$ ) & $60.3 \pm 64.6$ & $51.1 \pm 48.4$ & $63.8 \pm 70.2$ \\
\hline HLA-B5I+ (no/\%) & $26(52 \%)$ & $3(21 \%)$ & $23(64 \%)$ \\
\hline $\operatorname{ESR}(\mathrm{mm} / \mathrm{h} /$ mean $\pm \mathrm{SD})$ & $29.5 \pm 14.2$ & $28.6 \pm 13.8$ & $29.8 \pm 14.5$ \\
\hline $\mathrm{CRP}(\mathrm{mg} / \mathrm{dL} / \mathrm{mean} \pm \mathrm{SD})$ & $1.25 \pm 1.1$ & $0.84 \pm 0.7$ & $1.41 \pm 1.2$ \\
\hline Bilateral PU (no/\%) & $33(66 \%)$ & $12(86 \%)$ & $23(64 \%)$ \\
\hline Unilateral PU (no/\%) & $8(16 \%)$ & I (7\%) & $6(17 \%)$ \\
\hline Panuveitis (no/\%) & $9(18 \%)$ & I (7\%) & 7 (19\%) \\
\hline Retinal vasculitis (no/\%) & $31(62 \%)$ & $9(64 \%)$ & $22(6 \mid \%)$ \\
\hline Ocular attacks before IFX (total no/mean \pm SD) & $285(5.7 \pm 5.7)$ & $61(4.35 \pm 3.29)$ & $224(6.2 \pm 6.3)$ \\
\hline \multicolumn{4}{|l|}{ Previous treatment (no/\%) } \\
\hline$C S+A Z A$ & $14(28 \%)$ & $6(43 \%)$ & $8(22 \%)$ \\
\hline CS+MTX & $6(12 \%)$ & $2(14 \%)$ & $4(11 \%)$ \\
\hline $\mathrm{CS}+\mathrm{CSA}$ & $15(30 \%)$ & $5(36 \%)$ & $10(28 \%)$ \\
\hline $\mathrm{CS}+\mathrm{MTX}+\mathrm{CSA}$ & II (22\%) & I (7\%) & $10(28 \%)$ \\
\hline$C S+A Z A+C S A$ & $3(6 \%)$ & $0(0 \%)$ & $3(8 \%)$ \\
\hline$C S+M T X+C S A+A Z A$ & I (2\%) & $0(0 \%)$ & I (3\%) \\
\hline \multicolumn{4}{|l|}{ Ocular complications (no/\%) } \\
\hline Cataract & $9(18 \%)$ & $2(14 \%)$ & $7(19 \%)$ \\
\hline Cystoid macular edema & $19(38 \%)$ & $5(36 \%)$ & 14 (39\%) \\
\hline Retinal detachments & $4(8 \%)$ & I (7\%) & $3(8 \%)$ \\
\hline Papillitis & $8(16 \%)$ & $2(14 \%)$ & $6(17 \%)$ \\
\hline Intra/subretinal hemorrhage & $5(10 \%)$ & I (7\%) & $4(11 \%)$ \\
\hline Intravitreal hemorrhage & $3(6 \%)$ & I (7\%) & $2(5.5 \%)$ \\
\hline Optic atrophy & $5(10 \%)$ & I (7\%) & $4(11 \%)$ \\
\hline \multicolumn{4}{|l|}{ Visual acuity (mean $\pm S D)$} \\
\hline Right eye & $0.57 \pm 0.31$ & $0.6 \pm 0.31$ & $0.56 \pm 0.32$ \\
\hline Left eye & $0.67 \pm 0.28$ & $0.65 \pm 0.30$ & $0.68 \pm 0.27$ \\
\hline
\end{tabular}

Abbreviations: AZA, azathioprine; BD, Behçet's disease; CS, corticosteroids; CSA, cyclosporine A; IFX, infliximab; MTX, methotrexate; PU, posterior uveitis; SD, standard deviation. 
Table 2 Baseline and end of follow up results of IFX therapy in 50 patients overall with refractory PU

\begin{tabular}{|c|c|c|c|c|}
\hline Clinical feature & Baseline & $\begin{array}{l}\text { Week } 8 \\
\text { (After the 3rd IFX infusion) }\end{array}$ & End of follow-up & $P$ value \\
\hline \multicolumn{5}{|l|}{$\mathrm{PU}$ response to IFX (n/\%) } \\
\hline - Complete & & $29(58 \%)$ & $34(68 \%)$ & ns \\
\hline - Partial & & $16(32 \%)$ & II (22\%) & ns \\
\hline - Absent & & $5(10 \%)$ & $5(10 \%)$ & ns \\
\hline Proportion of patients with VA improvement (n/\%) & & $36(72 \%)$ & $4 \mathrm{I}(82 \%)$ & ns \\
\hline Relapse-free subjects $(\mathrm{n} / \%)$ & & $38 / 50(76 \%)$ & $31(62 \%)$ & ns \\
\hline \multicolumn{5}{|l|}{ Visual acuity (mean $\pm \mathrm{SD})$} \\
\hline Right eye & $0.57 \pm 0.31$ & $0.63 \pm 0.32$ & $0.68 \pm 0.33$ & 0.048 \\
\hline Left eye & $0.67 \pm 028$ & $0.74 \pm 0.26$ & $0.76 \pm 0.27$ & 0.047 \\
\hline Uveitis flares up (no/mean $\pm S D)$ & $285 / 5.70 \pm 5.6$ & NA & $38 / 0.76 \pm 1.11$ & 0.0001 \\
\hline Cystoid macular edema (no/\%) & $19(38 \%)$ & $14(28 \%)$ & $7(14 \%)$ & 0.008 \\
\hline FFA retinal vasculitis (no/\%) & $31(62 \%)$ & 12 (24\%) & 7 (I4\%) & 0.0001 \\
\hline
\end{tabular}

Abbreviations: FFA, fundus fluorescein angiography; IFX, infliximab; NA, not applicable; ns, not significant; PU, posterior uveitis; SD, standard deviation; VA, visual acuity.

IFX in BD compared to idiopathic PU did not disclose any significant difference for all outcome measures.

After a median interval from the beginning of the treatment at 8 months in seven (19\%) patients with BD and in three (21\%) patients with idiopathic PU, IFX dose escalation to 6-week infusion intervals was required due to uveitis flare up. After dose adjustment, a complete and stable uveitis remission was seen in eight out of ten $(80 \%)$ patients and two out of ten (20\%) achieved a partial response.

Regarding drug tolerability and safety, mild infusion reactions were recorded in nine $(18 \%)$ patients, urinary infections in six (12\%), upper airways infections in $11(16 \%)$, and slight liver enzymes in two (4\%) with no severe adverse event requiring IFX interruption. ANA positivity was observed in ten $(20 \%)$ patients during the whole period of follow-up, however no patients developed signs or symptoms of lupus-like syndrome.
The mean follow up duration for overall PU, BDassociated PU, and idiopathic PU was 36.8, 37.3, and 35.6, respectively.

\section{Discussion}

The efficacy of IFX on BD-associated and idiopathic refractory PU has been reported in single case report ${ }^{23-33}$ and in several clinical series (Table 4). To date, around 300 patients with refractory PU treated with IFX have been reported, with a favorable response rate ranging from $31 \%$ to $100 \%$ of cases. In almost all studies, the posterior eye inflammation suppression and the reduction of uveitis flare up have been adopted as the primary outcome measures. Two main considerations lead us to assume VA improvement as the primary end-point of the study. First, idiopathic and BD-associated PU represent an important cause of permanent VA reduction and blindness. Reduced VA and blindness are related to uncontrolled disease

Table 3 Results of IFX therapy divided by the diagnosis in 14 patients with idiopathic refractory PU and BD-associated PU and comparison between the two groups

\begin{tabular}{|c|c|c|c|c|c|c|c|}
\hline \multirow[t]{2}{*}{ Clinical feature } & \multicolumn{3}{|c|}{ Idiopathic PU (14 patients) } & \multicolumn{3}{|c|}{ BD-associated PU (36 patients) } & \multirow{2}{*}{$\begin{array}{l}\text { P } \\
\text { Id. PU vs BD }\end{array}$} \\
\hline & Baseline & $\begin{array}{l}\text { End of } \\
\text { follow-up }\end{array}$ & $\mathbf{P}$ & Baseline & $\begin{array}{l}\text { End of } \\
\text { follow-up }\end{array}$ & $\mathbf{P}$ & \\
\hline PU response (N/\%) & & & & & & & ns \\
\hline - Complete & & $9(64 \%)$ & & & $25(69 \%)$ & & \\
\hline - Partial & & $3(21 \%)$ & & & $8(22 \%)$ & & \\
\hline - Absent & & $2(14 \%)$ & & & $3(8 \%)$ & & \\
\hline Proportion of patients with & & II (79\%) & & & $30(83 \%)$ & & ns \\
\hline \multicolumn{8}{|l|}{ VA gain $(N / \%)$} \\
\hline Visual acuity (mean $\pm S D)$ & & & & & & & ns \\
\hline $\mathrm{RE}$ & $0.6 \pm 0.31$ & $0.70 \pm 0.31$ & 0.011 & $0.56 \pm 0.32$ & $0.65 \pm 0.33$ & 0.0005 & \\
\hline LE & $0.65 \pm 0.30$ & $0.75 \pm 0.29$ & 0.016 & $0.68 \pm 0.27$ & $0.76 \pm 0.27$ & 0.0004 & \\
\hline Uveitis flares up (no/mean $\pm S D$ ) & $6 \mathrm{I}(4.35 \pm 3.29)$ & $7(0.5 \pm 0.94)$ & 0.003 & $224(6.22 \pm 6.39)$ & $31 / 0.86 \pm 1.17$ & 0.0001 & ns \\
\hline Cystoid macular edema (no/\%) & $5(36 \%)$ & $0(0 \%)$ & 0.0003 & $14(39 \%)$ & $5(14 \%)$ & 0.03 & ns \\
\hline FFA retinal vasculitis (no/\%) & $9(64 \%)$ & I (7\%) & 0.0002 & $22(61 \%)$ & $2(5.5 \%)$ & 0.0001 & ns \\
\hline
\end{tabular}

Abbreviations: FFA, fundus fluorescein angiography; IFX, infliximab; NA, not applicable; ns, not significant; PU, posterior uveitis; SD, standard deviation; VA, visual acuity; $\mathrm{BD}$, Behçet's disease. 
Table 4 Reported clinical series of IFX therapy in patients with BD-associated or idiopathic refractory PU

\begin{tabular}{|c|c|c|c|c|c|c|}
\hline Reference & PU type & Patient $\mathbf{N}^{\circ}$ & IFX dose & $\begin{array}{l}\text { Primary outcome } \\
\text { measure }\end{array}$ & $\begin{array}{l}\text { Responders } \\
(\mathrm{N} / \%)\end{array}$ & $\begin{array}{l}\text { Follow-up } \\
\text { (months) }\end{array}$ \\
\hline Sfikakis et $\mathrm{al}^{34}$ & $\mathrm{BD}$ & 5 & $5 \mathrm{mg} / \mathrm{kg}$ & Inflammation suppression & $5(100 \%)$ & 1 \\
\hline Joseph et $\mathrm{al}^{35}$ & BD, idiopathic & 5 & $5 \mathrm{mg} / \mathrm{kg}$ & Inflammation suppression & $4(80 \%)$ & 6 \\
\hline Sfikakis et al ${ }^{36}$ & $\mathrm{BD}$ & 15 & $5 \mathrm{mg} / \mathrm{kg}$ & Inflammation suppression & $19(76 \%)$ & 8 \\
\hline Ohno et $\mathrm{al}^{37}$ & $\mathrm{BD}$ & 13 & $5 \mathrm{mg} / \mathrm{kg} / 10 \mathrm{mg} / \mathrm{kg}$ & Flare-up frequency & $10(77 \%)$ & 3 \\
\hline Wechsler et $\mathrm{al}^{38}$ & $\mathrm{BD}$ & 4 & $5 \mathrm{mg} / \mathrm{kg}$ & Inflammation suppression & $4(100 \%)$ & 22 \\
\hline Benitez-del Castillo et a ${ }^{39}$ & $\mathrm{BD}$, idiopathic & 7 & $5 \mathrm{mg} / \mathrm{kg}$ & Inflammation suppression & $4(57 \%)$ & 36 \\
\hline Tugal-Tutkun et al ${ }^{40}$ & $\mathrm{BD}$ & 13 & $5 \mathrm{mg} / \mathrm{kg}$ & Inflammation suppression & $4 / 13(31 \%)$ & 12 \\
\hline Lindstedt et $\mathrm{al}^{41}$ & $\mathrm{BD}$, idiopathic & 13 & $3 \mathrm{mg} / \mathrm{kg}$ & Inflammation suppression & $13 / 13(100 \%)$ & 24 \\
\hline Lanthier et al ${ }^{42}$ & $\mathrm{BD}$ & 4 & $5 \mathrm{mg} / \mathrm{kg}$ & Inflammation suppression & $2(50 \%)$ & 11 \\
\hline Suhler et $\mathrm{al}^{43}$ & BD, idiopathic & 23 & $5 \mathrm{mg} / \mathrm{kg}$ & See note* & $18(78 \%)$ & 2 \\
\hline Mushtaq B et $\mathrm{al}^{44}$ & $\mathrm{BD}$ & 3 & $5 \mathrm{mg} / \mathrm{kg}$ & Flare-up frequency & $3(100 \%)$ & 16 \\
\hline Abu El-Asrar AM ${ }^{45}$ & $\mathrm{BD}$ & 6 & $5 \mathrm{mg} / \mathrm{kg}$ & Inflammation suppression & $6(100 \%)$ & 36 \\
\hline Niccoli et al ${ }^{19}$ & $\mathrm{BD}$ & 12 & $5 \mathrm{mg} / \mathrm{kg}$ & Inflammation suppression & 7 (58\%) & 24 \\
\hline Accorinti et $\mathrm{al}^{46}$ & $\mathrm{BD}$ & 12 & $5 \mathrm{mg} / \mathrm{kg}$ & Flare-up frequency & II (92\%) & 16 \\
\hline \multirow[t]{2}{*}{ Tognon et $\mathrm{a}^{47}$} & $\mathrm{BD}$ & 7 & $3 \mathrm{mg} / \mathrm{kg}$ & Flare-up frequency & $6(86 \%)$ & 23 \\
\hline & & & $5 \mathrm{mg} / \mathrm{kg}$ & & & \\
\hline Al-Rayes et al ${ }^{48}$ & $\mathrm{BD}$ & 10 & $5 \mathrm{mg} / \mathrm{kg}$ & Flare-up frequency & $7(70 \%)$ & 36 \\
\hline Tabbara and Al-Hemidan ${ }^{49}$ & $\mathrm{BD}$ & 10 & $5 \mathrm{mg} / \mathrm{kg}$ & Flare-up frequency & NA & 30 \\
\hline Yamada et $\mathrm{al}^{50}$ & $\mathrm{BD}$ & 17 & $5 \mathrm{mg} / \mathrm{kg}$ & Flare-up frequency & & 6 \\
\hline Giardina et $\mathrm{al}^{51}$ & $\mathrm{BD}$ & 21 & $5 \mathrm{mg} / \mathrm{kg}$ & Inflammation suppression & I8 (86\%) & 12 \\
\hline Adán et $\mathrm{al}^{52}$ & $\mathrm{BD}$ & 4 & $5 \mathrm{mg} / \mathrm{kg}$ & Inflammation suppression & $2(50 \%)$ & 12 \\
\hline Yamada et $\mathrm{a}^{53}$ & $\mathrm{BD}$ & 23 & $5 \mathrm{mg} / \mathrm{kg}$ & Flare-up frequency & $10(43 \%)$ & 20 \\
\hline Sugita et $\mathrm{al}^{54}$ & $\mathrm{BD}$ & 20 & $5 \mathrm{mg} / \mathrm{kg}$ & Flare-up frequency & $15(75 \%)$ & 28 \\
\hline
\end{tabular}

Notes: *Patients were considered responders if improved in at least one of four variables (visual acuity, control of intraocular inflammation, ability to taper concomitant medication therapy, improvement in inflammatory signs on FFA and/or OCT) and if they worsened in none.

Abbreviations: BD, Behçet's disease; IFX, infliximab; NA, not applicable; PU, posterior uveitis; SD, standard deviation.

duration and respectively occur in up to $69 \%$ and $20 \%$ of the patients after 3 years. ${ }^{7,85,56}$ Therefore, the primary target of therapy of uveitis should be to avoid VA worsening and blindness. This concept has been recently underlined in the Multicenter Uveitis Steroid Treatment (MUST) Trial study design. ${ }^{57}$ Second, the reproducibility of criteria for grading the site and the activity of intraocular inflammation is rather low, ${ }^{58}$ unless laser flare-cell photometry is used to quantify and compare the severity of uveitis. ${ }^{59}$

In our long-term, prospective study of IFX efficacy in refractory PU, VA improved in 41 out of 50 (82\%) patients, with significant improvement of mean VA values at the end of follow up compared to baseline. Of note, in keeping with other studies, ${ }^{60}$ IFX was rapidly effective as demonstrated by the dramatic improvement of ocular inflammatory changes and VA after the third infusion in the majority of the patients (78\%) and by the elevated number of patients achieving complete $(58 \%)$ or partial remission (32\%) at the same time. Moreover, the drug maintained its efficacy overtime even if a dose escalation was required in ten out of 45 patients (22\%).

The secondary outcome measures including the proportion of patients achieving disease remission, retinal vasculitis, and the frequency of uveitis relapse also improved significantly.
Moreover, confirming the results of other studies, ${ }^{61} \mathrm{CME}$ resolved in 12 of $19(63 \%)$ patients $(P=0.008)$ after a mean follow-up of 36.8 months.

Epidemiological data indicate that idiopathic PU account for at least $35 \%$ of noninfectious PU and panuveitis. ${ }^{6}$ Similarly to BD-associated PU, idiopathic PU are immunomediated conditions of the posterior segment resistant to combined CS and immunosuppressive drug therapy in $20 \%$ to $30 \%$ of patients, ${ }^{7,12,62}$ and with a frequency of visual impairment and blindness not different from that found for uveitis of known etiology. ${ }^{55}$ In several clinical series of IFX in refractory $\mathrm{PU}$, both patients with $\mathrm{BD}$ and idiopathic $\mathrm{PU}$ were included. ${ }^{35,39,41,43}$ The results of these studies were not divided by the etiology of PU with no specific information concerning the efficacy of IFX in patients with idiopathic PU. In our study, IFX was effective in patients with idiopathic PU with significant improvement of all outcome measures with respect to baseline, and there were no significant differences of efficacy in comparison with patients with BD.

As regards its safety profile, long-term IFX therapy was well-tolerated with minor infusion-related reactions occurring in a minority of the patients and absence of serious adverse events requiring drug discontinuation. 
A limit to our study is the open-label design that reduces the level of evidence. To date, IFX has been employed only in patients with refractory uveitis and with established, not reversible ocular complications in most cases. In a recent retrospective, 6-month study from Japan,,$^{50}$ IFX was significantly more effective than CsA to reduce the frequency of ocular attacks in BD patients with refractory uveitis. We suggest randomized controlled trials to evaluate the efficacy of IFX compared to traditional therapy to preserve visual acuity in patients with autoimmune $\mathrm{PU}$ at onset.

In conclusion, the results of the current long-term study confirm that IFX has a rapid and sustained efficacy in a high proportion of patients with BD-associated and idiopathic refractory PU allowing a significant improvement of VA in $82 \%$ of the patients, with a complete disease remission rate of $68 \%$ of cases. The separated data analysis indicates that IFX is equally effective both in patients with idiopathic PU and those with BD. The safety profile of the drug was good with no serious AEs reported.

\section{Disclosure}

The authors report no conflicts of interest in this work.

\section{References}

1. Perkins ES, Folk J. Uveitis in London and Iowa. Ophthalmologica. 1984;189:36-40.

2. Henderly DE, Genstler AJ, Smith RE, Rao NA. Changing patterns of uveitis. Am J Ophthalmol. 1987;103:131-136.

3. Weiner A, BenEzra D. Clinical patterns and associated conditions in chronic uveitis. Am J Ophthalmol. 1991;112:151-158.

4. Rodriguez A, Calonge M, Pedroza-Seres M, et al. Referral patterns of uveitis in a tertiary eye care center. Arch Ophthalmol. 1996;114:593-599.

5. Jabs DA, Nussenblatt RB, Rosenbaum JT; Standardization of Uveitis Nomenclature (SUN) Working Group. Standardization of uveitis nomenclature for reporting clinical data. Results of the first international workshop. Am J Ophthalmol. 2005;140:509-516.

6. Rathinam SR, Namperumalsamy P. Global variation and pattern changes in epidemiology of uveitis. Indian J Ophthalmol. 2007;55(3):173-183.

7. Kaçmaz RO, Kempen JH, Newcomb C, et al. Ocular inflammation in Behçet disease: incidence of ocular complications and of loss of visual acuity. Am J Ophthalmol. 2008;146:828-836.

8. Kump LI, Moeller KL, Reed GF, Kurup SK, Nussenblatt RB, Levy-Clarke GA. Behçet's disease: comparing 3 decades of treatment response at the National Eye Institute. Can J Ophthalmol. 2008;43: $468-472$.

9. Tugal-Tutkun I, Onal S, Altan-Yaycioglu R, Huseyin Altunbas H, Urgancioglu M. Uveitis in Behçet disease: an analysis of 880 patients. Am J Ophthalmol. 2004;138:373-380.

10. Pato E, Muñoz-Fernández S, Francisco F, Abad MA, Maese J, OrtizA, et al. Systematic review on the effectiveness of immunosuppressants and biological therapies in the treatment of autoimmune posterior uveitis. Semin Arthritis Rheum. 2011;40:314-323.

11. Ilhan F, Demir T, Türkçüoğlu P, Turgut B, Demir N, Gödekmerdan A. Th1 polarization of the immune response in uveitis in Behçet's disease. Can J Ophthalmol. 2008;43:105-108.
12. Ahad MA, Missotten T, Abdallah A, Lympany PA, Lightman S. Polymorphisms of chemokine and chemokine receptor genes in idiopathic immune-mediated posterior segment uveitis. Mol Vis. 2007;13:388-396.

13. Okada AA, Sakai J, Usui M, et al. Intraocular cytokine quantification of experimental autoimmune uveoretinitis in rats. Ocul Immunol Inflamm. 1998;6:111-120.

14. Calder VL, Shaer B, Muhaya M, et al. Increased CD4+ expression and decreased IL-10 in the anterior chamber in idiopathic uveitis. Invest Ophthalmol Vis Sci. 1999;40:2019-2024.

15. Robertson M, Liversidge J, Forrester JV, et al. Neutralizing tumor necrosis factor-alpha activity suppresses activation of infiltrating macrophages in experimental autoimmune uveoretinitis. Invest Ophthalmol Vis Sci. 2003;44:3034-3041.

16. Greiner K, Murphy CC, Willermain F, et al. Anti-TNFalpha therapy modulates the phenotype of peripheral blood CD4+ T cells in patients with posterior segment intraocular inflammation. Invest Ophthalmol Vis Sci. 2004;45:170-176.

17. Santos Lacomba M, Marcos Martin C, Gallardo Galera JM, et al. Aqueous humor and serum tumor necrosis factor-alpha in clinical uveitis. Ophthalmic Res. 2001;33:251-255.

18. Larson T, Nussenblatt RB, Sen HN. Emerging drugs for uveitis. Expert Opin Emerg Drugs. 2011;16:309-322.

19. Niccoli L, Nannini C, Benucci M, et al. Long-term efficacy of infliximab in refractory posterior uveitis of Behçet's disease: a 24-month follow-up study. Rheumatology (Oxford). 2007;46(7):1161-1164.

20. Jabs DA, Rosenbaum JT, Foster CS, et al. Guidelines for the use of immunosuppressive drugs in patients with ocular inflammatory disorders: recommendations of an expert panel. Am J Ophthalmol. 2000;130:492-513.

21. International Study Group for Behçet's disease. Criteria for diagnosis of Behçet's disease. Lancet. 1990;335:1078-1080.

22. Tugal-Tutkun I. Behçet's uveitis. Middle East Afr J Ophthalmol. 2009;16:219-224.

23. Goossens PH, Verburg RJ, Breedveld FC. Remission of Behçet's syndrome with tumour necrosis factor alpha blocking therapy. Ann Rheum Dis. 2001;60:637.

24. Muñoz-Fernández S, Hidalgo V, Fernández-Melón J, Schlincker A, Martín-Mola E. Effect of infliximab on threatening panuveitis in Behçet's disease. Lancet. 2001;358:1644.

25. Triolo G, Vadalà M, Accardo-Palumbo A, et al. Anti-tumour necrosis factor monoclonal antibody treatment for ocular Behçet's disease. Ann Rheum Dis. 2002;61:560-561.

26. Morris DS, Gavin MP, Sturrock RD. The effect of anti-tumour necrosis factor alpha (infliximab) on sight-threatening uveitis in a patient with Behçet's disease. Adv Exp Med Biol. 2003;528:557-559.

27. Giansanti F, Barbera ML, Virgili G, Pieri B, Emmi L, Menchini U. Infliximab for the treatment of posterior uveitis with retinal neovascularization in Behçet disease. Eur J Ophthalmol. 2004;14:445-448.

28. Takamoto M, Kaburaki T, Numaga J, Fujino Y, Kawashima H. Longterm infliximab treatment for Behçet's disease. Jpn J Ophthalmol. 2007;51:239-240.

29. Olivieri I, Latanza L, Siringo S, Peruz G, Di Iorio V. Successful treatment of severe Behçet's disease with infliximab in an Italian Olympic athlete. J Rheumatol. 2008;35:930-932.

30. Olivieri I, Padula A, Leccese P, D’Angelo S, Giasi V. Long-lasting remission of severe Behçet's disease after the end of infliximab therapy. J Rheumatol. 2009;36:855.

31. Alokaily F, Alsaleh S, Al-Balawi M, Al-Rashidi S. Efficacy of infliximab on the acute attack of uveitis. Saudi Med J. 2010;31:82-85.

32. Donghi D, Mainetti C. Infliximab for the treatment of refractory Adamantiades-Behçet disease with articular, intestinal, cerebral and ocular involvement. Dermatology. 2010;220:282-286.

33. Kawaguchi T, Sugita S, Yamada Y, Miyanaga M, Mochizuki M. Regression of optic disc neovascularization in patients with Behçet's uveoretinitis after infliximab therapy. $J$ Ocul Pharmacol Ther. 2010;26:627-630. 
34. Sfikakis PP, Theodossiadis PG, Katsiari CG, Kaklamanis P, Markomichelakis NN. Effect of infliximab on sight-threatening panuveitis in Behçet's disease. Lancet. 2001;358:295-296.

35. Joseph A, Raj D, Dua HS, Powell PT, Lanyon PC, Powell RJ. Infliximab in the treatment of refractory posterior uveitis. Ophthalmology. 2003;110:1449-1453.

36. Sfikakis PP, Kaklamanis PH, Elezoglou A, et al. Infliximab for recurrent, sight-threatening ocular inflammation in Adamantiades-Behçet disease. Ann Intern Med. 2004;140:404-406.

37. Ohno S, Nakamura S, Hori S, et al. Efficacy, safety, and pharmacokinetics of multiple administration of infliximab in Behçet's disease with refractory uveoretinitis. J Rheumatol. 2004;31:1362-1368.

38. Wechsler B, Sablé-Fourtassou R, Bodaghi B, et al. Infliximab in refractory uveitis due to Behçet's disease. Clin Exp Rheumatol. 2004;22(4 Suppl 34):S14-S16.

39. Benitez-del-Castillo JM, Martinez-de-la-Casa JM, Pato-Cour E, et al. Long-term treatment of refractory posterior uveitis with anti-TNFalpha (infliximab). Eye (Lond). 2005;19:841-845.

40. Tugal-Tutkun I, Mudun A, Urgancioglu M, et al. Efficacy of infliximab in the treatment of uveitis that is resistant to treatment with the combination of azathioprine, cyclosporine, and corticosteroids in Behçet's disease: an open-label trial. Arthritis Rheum. 2005;52:2478-2484.

41. Lindstedt EW, Baarsma GS, Kuijpers RW, van Hagen PM. Anti-TNF-alpha therapy for sight threatening uveitis. Br J Ophthalmol. 2005;89:533-536.

42. Lanthier N, Parc C, Scavennec R, Dhôte R, Brézin AP, Guillevi L. Infliximab in the treatment of posterior uveitis in Behçet's disease. Long term follow up in four patients. Presse Med. 2005;34:916-918.

43. Suhler EB, Smith JR, Wertheim MS, et al. A prospective trial of infliximab therapy for refractory uveitis: preliminary safety and efficacy outcomes. Arch Ophthalmol. 2005;123:903-912.

44. Mushtaq B, Saeed T, Situnayake RD, Murray PI. Adalimumab for sight-threatening uveitis in Behçet's disease. Eye (Lond). 2007;21:824-825.

45. Abu El-Asrar AM, Abboud EB, Aldibhi H, Al-Arfaj A. Long-term safety and efficacy of infliximab therapy in refractory uveitis due to Behçet's disease. Int Ophthalmol. 2005;26:83-92.

46. Accorinti M, Pirraglia MP, Paroli MP, Priori R, Conti F, Pivetti-Pezzi P. Infliximab treatment for ocular and extraocular manifestations of Behçet's disease. Jpn J Ophthalmol. 2007;51:191-196.

47. Tognon S, Graziani G, Marcolongo R. Anti-TNF-alpha therapy in seven patients with Behçet's uveitis: advantages and controversial aspects. Ann NY Acad Sci. 2007;1110:474-484.

48. Al-Rayes H, Al-Swailem R, Al-Balawi M, Al-Dohayan N, Al-Zaidi S, Tariq M. Safety and efficacy of infliximab therapy in active Behçet's uveitis: an open-label trial. Rheumatol Int. 2008;29:53-57.
49. Tabbara KF, Al-Hemidan AI. Infliximab effects compared to conventional therapy in the management of retinal vasculitis in Behçet disease. Am J Ophthalmol. 2008;146:845-850.

50. Yamada Y, Sugita S, Tanaka H, Kamoi K, Kawaguchi T, Mochizuki M. Comparison of infliximab versus cyclosporin during the initial 6-month treatment period in Behçet disease. Br J Ophthalmol. 2010;94:284-288.

51. Giardina A, Ferrante A, Ciccia F, Vadalà M, Giardina E, Triolo G. One year study of efficacy and safety of infliximab in the treatment of patients with ocular and neurological Behçet's disease refractory to standard immunosuppressive drugs. Rheumatol Int. 2011;31:33-37.

52. Adán A, Hernandez V, Ortiz S, et al. Effects of infliximab in the treatment of refractory posterior uveitis of Behçet's disease after withdrawal of infusions. Int Ophthalmol. 2010;30(5):577-581.

53. Yamada Y, Sugita S, Tanaka H, Kamoi K, Takase H, Mochizuki M. Timing of recurrent uveitis in patients with Behcet's disease receiving infliximab treatment. Br J Ophthalmol. 2011;95:205-208.

54. Sugita S, Yamada Y, Mochizuki M. Relationship between serum infliximab levels and acute uveitis attacks in patients with Behçet disease. Br J Ophthalmol. 2011;95:549-552.

55. Rothova A, Suttorp-van Schulten MS, Frits Treffers W, Kijlstra A. Causes and frequency of blindness in patients with intraocular inflammatory disease. Br J Ophthalmol. 1996;80:332-336.

56. Durrani OM, Tehrani NN, Marr JE, Moradi P, Stavrou P, Murray PI. Degree, duration, and causes of visual loss in uveitis. Br J Ophthalmol. 2004;88:1159-1162.

57. The Multicenter Uveitis Steroid Treatment Trial Research Group, Kempen JH, Altaweel MM, Holbrook JT, Jabs DA, Sugar EA. The multicenter uveitis steroid treatment trial: rationale, design and baseline characteristics. Am J Ophthalmol. 2010;149:550-561.

58. Kempen JH, Ganesh SK, Sangwan VS, Rathinam SR. Interobserver agreement in grading activity and site of inflammation in eyes of patients with uveitis. Am J Ophthalmol. 2008;146:813-818.

59. Tugal-Tutkun I, Cingu K, Kir N, Yeniad B, Urgancioglu M, Gul A. Use of laser flare-cell photometry to quantify intraocular inflammation in patients with Behçet's uveitis. Graefes Arch Clin Exp Ophthalmol. 2008;246:1169-1177.

60. Sfikakis PP. The first decade of biologic TNF antagonists in clinical practice: lessons learned, unresolved issues and future directions. Curr Dir Autoimmun. 2010;11:180-210.

61. Markomichelakis NN, Theodossiadis PG, Pantelia E, Papaefthimiou S, Theodossiadis GP, Sfikakis PP. Infliximab for chronic cystoid macular edema associated with uveitis. Am J Ophthalmol. 2004;138:648-650.

62. de Vries J, Baarsma GS, Zaal MJW, et al. Cyclosporin in the treatment of severe chronic idiopathic uveitis. Br J Ophthalmol. 1990;74:344-349.
Biologics: Targets \& Therapy

\section{Publish your work in this journal}

Biologics: Targets \& Therapy is an international, peer-reviewed journal focusing on the patho-physiological rationale for and clinical application of Biologic agents in the management of autoimmune diseases, cancers or other pathologies where a molecular target can be identified. This journal is indexed on PubMed Central, CAS, EMBase, Scopus

\section{Dovepress}

and the Elsevier Bibliographic databases. The manuscript management system is completely online and includes a very quick and fair peerreview system, which is all easy to use. Visit http://www.dovepress. com/testimonials.php to read real quotes from published authors. 